\title{
Effect of Intravenous Patient Controlled Ketamine Analgesiaon Postoperative Pain in Opium Abusers
}

\author{
Mastane Dahi-Taleghani ${ }^{1}$; Benjamin Fazli ${ }^{1}$; Mahshid Ghasemi ${ }^{1}$; Maryam Vosoughian ${ }^{1}$; Ali \\ Dabbagh ${ }^{1, *}$ \\ ${ }^{1}$ Anesthesiology Research Center, Shahid Beheshti University of Medical Sciences, Tehran, Iran \\ ${ }^{*}$ Corresponding author: Ali Dabbagh, Anesthesiology Research Center, ShahidBeheshti University of Medical Sciences, Tehran, Iran. Tel: +98-989121972368, Fax: +98-982122432572, \\ E-mail:alidabbagh@yahoo.com, Email: alidabbagh@sbmu.ac.ir
}

Received: August 10, 2013; Revised: November 22, 2013; Accepted: December 1, 2013

\begin{abstract}
Background: Acutepostoperative pain is among the worst experience that patient scan undergo, and many analgesics have been used to suppress it; especially in chronic opium abusers. Ketamine is an N-methyl-D-aspartate antagonist analgesic, having both anesthetic and analgesic properties, which are not affected to the same extent in chronic opium abusers.

Objectives: In this study, we assessed the analgesic effects of ketamine added to morphine as a patient-controlled analgesia method for acute pain management, compared with a placebo, inchronic maleopium abusers.

Patients and Methods: After institutional review board approval for ethical considerations, a randomized double-blinded placebo controlled clinical trial was conducted. A total of 140 male patients aged 18-65 years, undergoing orthopedic surgery, were entered into the study after matching inclusion and exclusion criteria. All patients received the same anesthesia method; while the first group received ketamine $(1 \mathrm{mg} / \mathrm{mL})$ and morphine $(0.5 \mathrm{mg} / \mathrm{mL})$ as a patient-controlled analgesia (70 patients), the second group received morphine (0.5 $\mathrm{mg} / \mathrm{mL}$ ) plus normal saline (70 patients). P value less than 0.05 was considered statistically significant.

Results: The ketamine and morphine group of patients experienced less postoperative pain and required less postoperative rescue analgesia. However, the unwanted postoperative side effects were nearly the same; although increased levels of postoperative nausea and vomiting were observed in the ketamine and morphine group

Conclusions: This study demonstrated improved analgesic effects after using intravenous patient controlled analgesia with ketamine on postoperative pain in opium abusers.
\end{abstract}

Keywords: Ketamine; Acute Pain; Opium; Drug Users

\section{Background}

Acute postoperative pain is one of the most difficult experiences that patients must tolerate. Many different analgesics have been used; each having their own special drawbacks (1). Among patients with acute pain, chronic opium abusers are a real challenge (2-5), as they usually need extremely high doses of analgesics for acute pain suppression, and in addition, some analgesics are not very effective on them $(6,7)$. To resolve this problem, many analgesics have been tested with controversial results.

Ketamine is an N-methyl-D-aspartate antagonist (8-10), and it is mainly used as an anesthetic with simultaneous analgesic properties. Since it is an NMDA antagonist and its analgesic properties do not stimulate opioid receptors, it induces analgesia through NMDA receptors instead, which is a more effective mechanism in opium abusers (10-18). Although there are some controversies regarding ketamine (19-22), recent clinical studies have demonstrated its effectiveness as an analgesic agent in opium abusers (11). However, the analgesic effects of ketamine in improving clinical outcomes in opium abusers, especially when used as a patient controlled analgesia (PCA), are not well defined and need more research (23).

\section{Objectives}

In this study, we assessed the analgesic effects of ketamine when added to a morphine sulfate solution as a PCA method for acute pain management, compared with a placebo in male patients with a history of chronic opium abuse.

\section{Patients and Methods}

This was a randomized double-blinded placebo con-

Implication for health policy/practice/research/medical education:

In opium abusers, the management of acute postoperative pain is a challenging task; mainly due to chronic exposure of the patients with the analgesic drugs; however, this study demonstrated that using intravenous patient controlled analgesia with ketamine could improve the analgesic effects of our medications regarding acute postoperative pain.

Copyright @ 2014, Iranian Society of Regional Anesthesia and Pain Medicine(ISRAPM); Published by KowsarCorp. This is an open-access article distributed under the terms of the Creative Commons Attribution License, which permits unrestricted use, distribution, and reproduction in any medium, provided the original work is properly cited. 
trolled clinical trial. The proposal of the study was approved for ethical considerations by the institutional review board of Shahid Beheshti University of Medical Sciences, Tehran, Iran. Furthermore, the manuscript was approved by the Ethics Committee, Research Deputy, Shahid Beheshti University of Medical Sciences and the following comments were followed throughout all stages of the study:

1) The study protocol conforms to the ethical guidelines of the 1975 Declaration of Helsinki.

2) Informed written consent was taken from each patient separately, before entering the study

\subsection{Patient Selection and Sample Size Calculation}

All male patients, aged 18-65 years undergoing orthopedic surgery in a university hospital, were considered as the target population. After considering the inclusion and exclusion criteria and calculating the sample size, the patients entering the study were selected. The inclusion criteria consisted of; male gender, elective orthopedic surgery of the lower limb, history of opium abuse (inhalational or oral routes, on a regular basis for at least two years, leading to drug craving behaviors in case of drug deprivation, all based on the patient's declaration), application of general anesthesia, no contraindication for general anesthesia, and having no significant co-morbid disease (i.e. all were American Society of Anesthesiology (ASA) class I or II patients). The exclusion criteria included; female gender, other anesthetic methods (except for general anesthesia), ASA class more than III, duration of anesthesia less than one hour, other routes of drug abuse (except for inhalational opium for two years), and patient's refusal to continue the study after primary approval for study entry. The patients were then randomly assigned to one of the two study groups based on a computer table of random numbers:

1) The first group consisted of 70 patients who received ketamine plus morphine (KM group) as a PCA method. In this group, a combined solution of $1 \mathrm{mg} / \mathrm{mL}$ ketamine and $0.5 \mathrm{mg} / \mathrm{mL}$ morphine was prepared as the PCA analgesia protocol. This was started immediately in the postoperative period, at 10 minutes intervals, and each bolus contained $2 \mathrm{~mL}$ of the solution (i.e. $2 \mathrm{mg}$ ketamine plus 1 mg morphine).

2) The second group also consisted of 70 patients, and they received a combination of morphine $(0.5 \mathrm{mg} / \mathrm{mL})$ plus normal saline solution (M group). Again, PCA analgesia was started immediately in the postoperative period at 10 minutes intervals, using $2 \mathrm{~mL}$ of the solution in each PCA bolus (i.e. $1 \mathrm{mg}$ morphine in each bolus). A brief presentation of these stages is demonstrated in Figure 1.

Sample size determination was done after a power analysis (power $=0.8 ; \beta=0.2 ; \alpha=0.02$ ) using sample size software (PASS 2005, NCSS LLC, Kaysville, Utah, USA). The observed frequency for acute postoperative pain in simi- lar patients requesting analgesics was also considered as the clinical criterion for determination of the sample size, and based on the following data and sample size equation (24-27):

$$
\mathrm{n}=2\left[\left(\mathrm{Z}_{\beta}+\mathrm{Z}_{\alpha}\right) \sigma / \Delta\right]^{2}
$$

Where:

-n ( sample size in each group) $=62$

$\bullet \alpha=0.05$

$\cdot \mathrm{Z} \alpha=1.96$

$\bullet \beta=0.2$

$\cdot \mathrm{Z} \beta=0.84$

- $\sigma$ (estimated standard deviation based on similar studies) $=2$

- $\Delta=$ the estimated effect size (i.e. the minimal difference desired between the two study interventions or the clinical outcomes of the two groups)

Considering a possible $10 \%$ dropout, 70 patients were considered as the sample size for each study arm, and consequently total number of 140 patients were selected and entered the study after matching the inclusion and exclusion criteria as follows.

\subsection{Clinical Management of Patients}

All patients were visited the night before surgery and the study protocol was described to them. This visit was the task of the authors 'colleague. He explained the process of the study and took informed written consents for entering the study during this visit. He also explained that entering the study was a completely voluntary issue and any patient entering the study could exit the research process at any time during the study period. In addition, acceptance or refusal to enter the study, or refusal to continue, had no effect on the treatment process (including the treatment of acute pain).

The patients underwent general anesthesia for elective lower limb orthopedic surgery. After entering the operating theatre their vital signs were monitored using; electrocardiogram, pulse oximeter, end tidal $\mathrm{CO}_{2}$, and noninvasive blood pressure. For each patient, two intravenous lines were inserted for the administration of fluids, blood and drugs, all according to the study's protocol and the patient's needs. Anesthesia was induced using $0.2 \mathrm{mg} /$ $\mathrm{Kg}$ IV midazolam, $200 \mu \mathrm{g}$ fentanyl, $5 \mathrm{mg} / \mathrm{Kg}$ sodium thiopental, and $5 \mathrm{mg} / \mathrm{Kg}$ atracurium. Before anesthesia induction, $10 \mathrm{ml} / \mathrm{Kg}$ of Ringer's solution was administered freely to compensate for NPO time deficit. For maintenance of the anesthesia, 0.6-1\% isoflurane was used to keep the anesthesia depth between 40-60, using Bispectral Index (BIS) monitoring. During final skin suturing, isoflurane was discontinued, and the patients were reversed pharmacologically, using $0.05 \mathrm{mg} / \mathrm{kg}$ neostigmine plus 0.02 $\mathrm{mg} / \mathrm{Kg}$ atropine. After full muscle force recovery and an appropriate level of consciousness, the patients were extubated. Ketamine was not used for anesthesia induction or maintenance at any time during the study. The pa- 
tients were transferred to the postanaesthetic care unit (PACU) for hemodynamic control, and regaining a full level of consciousness before starting acute pain control remedies.

During the postoperative period, the patients' postoperative pain scores were controlled using a visual analog scale (VAS), and their respiratory status; using pulse oximetry and respiratory rates, were measured. Postoperative pain was documented and registered at 1, 6 and 24 hours after the operation. In addition the patients received supplementary nasal oxygen, if they had any decline of oxygen saturation $\left(\mathrm{SpO}_{2}\right)$ below 92\%. However, postoperative pain scores greater than 3 out of 10 , mandated postoperative pain control using analgesics through the following protocol:

1) Starting PCA as defined in the patient groupings (KM group vs. M group).

2) Respiratory monitoring including pulse oximetry.

3) Adding supplementary nasal oxygen if $\mathrm{SpO}_{2}$ was less than $92 \%$.

4) Administration of supplementary intravenous morphine to each of the patients having a VAS score more than 3 out of 10 in the postoperative period, regardless of their study group.

5) Calculating the extra morphine doses in each patient during the first 24 hour period after the operation.

6) Assessment of postoperative nausea and vomiting frequencies in each patient in the first 24 hour period after the operation.

Data were collected and analyzed using SPSS software, (version 16). A Student's t-test was used for data analysis. P value less than 0.05 were considered statistically significant.

\section{Results}

The two study groups had no significant difference regarding baseline demographic data (Table 1). While the results of postoperative pain scores were lower in the KM group, they also experienced less postoperative pain, and needed less postoperative rescue analgesia (Tables 2 and 3) These results suggest a greater analgesic effect of the PCA solution used in the KM patient group. However, the unwanted postoperative side effects were very similar; although increased postoperative nausea and vomiting was observed in the KM group (Table 4).

A summary of the study stages are presented in the following diagram:

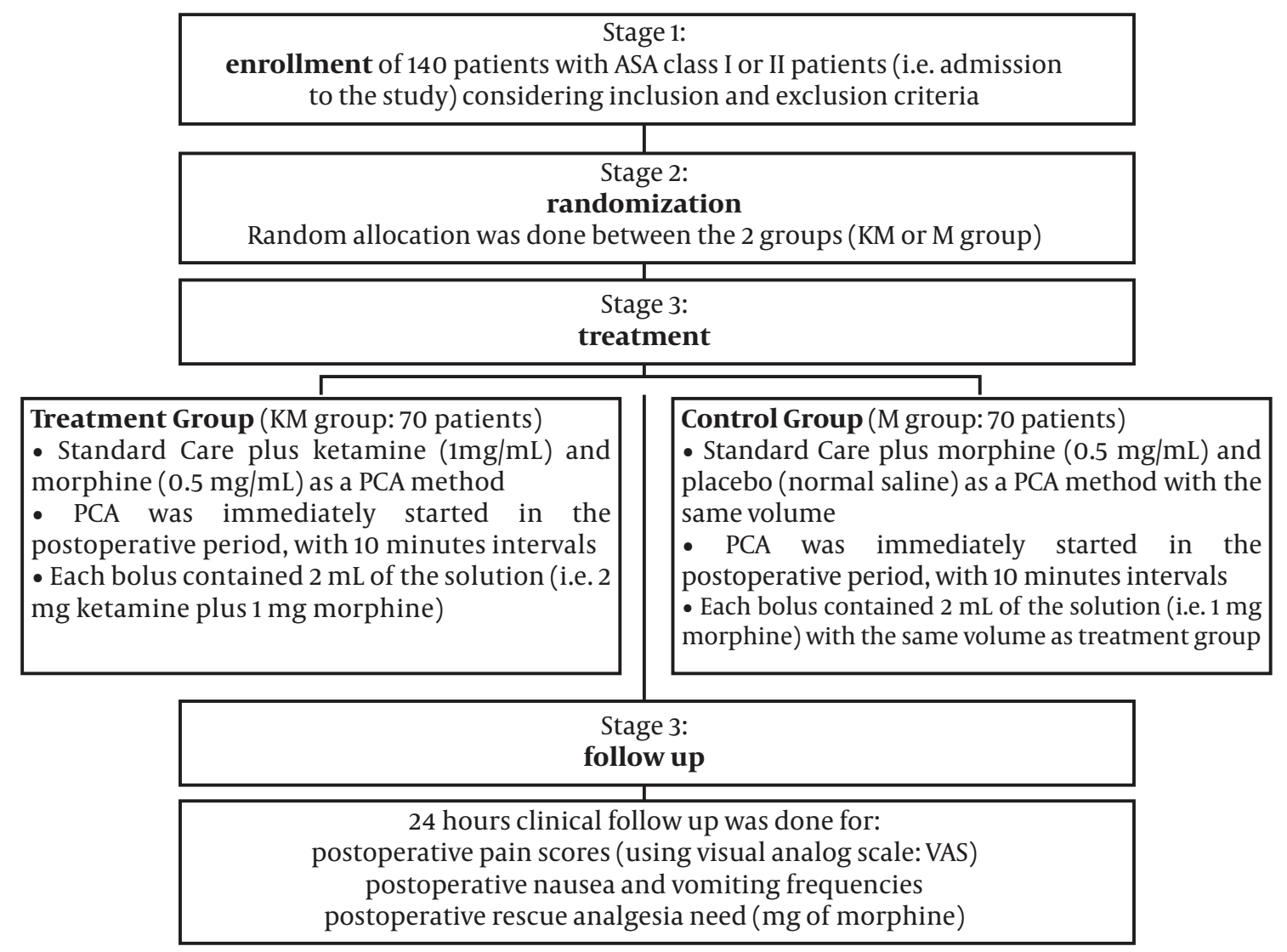


Figure 1. Summary of the Study Stages are Presented in the Diagram

\begin{tabular}{|c|c|c|c|}
\hline & KM Group $^{\mathrm{a}}$, Mean $\pm S D,(n=70)$ & M Group $^{\text {a }}$, Mean $\pm S D,(n=70)$ & Pvalue \\
\hline Age, $y$ & $39.1 \pm 7.2$ & $38.3 \pm 7.5$ & $>0.05$ \\
\hline Weight, kg & $68.8 \pm 12.5$ & $69.6 \pm 11.1$ & $>0.05$ \\
\hline Operation time, min & $98 \pm 18$ & $94 \pm 20$ & $>0.05$ \\
\hline Anesthesia time, min & $132 \pm 24$ & $126 \pm 26$ & $>0.05$ \\
\hline
\end{tabular}

a KM group; $1 \mathrm{mg} / \mathrm{mL}$ ketamine and $0.5 \mathrm{mg} / \mathrm{mL}$ morphine solution; $\mathrm{M}$ group; $0.5 \mathrm{mg} / \mathrm{mL}$ morphine plus normal saline solution.

\begin{tabular}{|c|c|c|c|}
\hline & KM Group $^{\mathrm{a}}$, Mean $\pm S D,(n=70)$ & M Group $^{\mathrm{a}}$, Mean $\pm S D,(n=70)$ & Pvalue \\
\hline VAS Score 1 hour After Surgery & $2.4 \pm 1.1$ & $3.6 \pm 1.3$ & 0.01 \\
\hline VAS Score 6 hours After Surgery & $1.5 \pm 0.8$ & $2.2 \pm 1.1$ & 0.03 \\
\hline VAS Score 24 hours After Surgery & $1 \pm 0.5$ & $1.7 \pm 0.8$ & 0.02 \\
\hline
\end{tabular}

${ }^{\mathrm{a}}$ KM group; $1 \mathrm{mg} / \mathrm{mL}$ ketamine and $0.5 \mathrm{mg} / \mathrm{mL}$ morphine solution; $\mathrm{M}$ group; $0.5 \mathrm{mg} / \mathrm{mL}$ morphine plus normal saline solution.

\begin{tabular}{llll}
\hline \multicolumn{1}{l}{ Table 3. Postoperative Rescue Analgesia in the Two Study Groups } \\
\hline & KM Group $^{\text {a }}$, Mean $\pm \mathbf{S D},(\mathbf{n}=\mathbf{7 0})$ & M Group $^{\text {a }}$, Mean $\pm \mathbf{S D},(\mathbf{n}=\mathbf{7 0})$ & P value \\
\hline Morphine, $\mathbf{m g}$ (Total 24 Hourdose) & $12 \pm 3$ & $7 \pm 2$ & 0.01 \\
\hline
\end{tabular}

a KM group; $1 \mathrm{mg} / \mathrm{mL}$ ketamine and $0.5 \mathrm{mg} / \mathrm{mL}$ morphine solution; M group; 0.5mg/mL morphine plus normal saline solution.

\begin{tabular}{|c|c|c|c|}
\hline & $\begin{array}{l}\text { KM Group }{ }^{\mathrm{a}}, \text { Frequency (\%), } \\
(\mathbf{n}=70)\end{array}$ & $\begin{array}{l}\text { M Group }{ }^{a}, \text { Frequency (\%), } \\
(\mathbf{n}=70)\end{array}$ & Pvalue for Chi Square \\
\hline Nausea & $10(14)$ & $4(6)$ & 0.03 \\
\hline Vomiting & $6(8.5)$ & $1(1.5)$ & 0.02 \\
\hline Patients requiring an antiemetic & $8(11.5)$ & $3(4)$ & 0.02 \\
\hline
\end{tabular}

${ }^{\mathrm{a}}$ KM group; $1 \mathrm{mg} / \mathrm{mL}$ ketamine and $0.5 \mathrm{mg} / \mathrm{mL}$ morphine solution; M group; 0.5mg/mL morphine plus normal saline solution.

\section{Discussion}

The results of this study demonstrated improved analgesic effects of intravenous patient controlled analgesia with ketamine on postoperative pain in opium abusers. The effects of chronic opium abuse in altering the threshold of pain tolerance have previously been studied in a number of studies since the issue became a high priority in acute pain research $(2,4,6,7,28-32)$. On the other hand, among this large list, there are not many studies that have assessed the effects of ketamine in postoperative pain suppression in these patients $(17,33)$.

There is no doubt that acute pain treatment in such patients is a real challenge $(33,34)$ and the usual pain killers (including; opioid agents, NSAIDs or even regional analgesic techniques) have less analgesic effects on them compared to the general population $(5-7,32,33$, 35). Previous studies have demonstrated other clinical problems in opium abusing patients, especially when they are managed for their acute pain status $(2,4,7,32$, $33,36)$. Ketamine, an NMDA antagonist, acts through its specific receptors which are not frequently exposed to drugs abused by these patients before their surgery (17, $34,37-39)$. This is possibly one of the main explanations justifying our findings regarding the acceptable effects of ketamine in opium abusers. Results of the present study also demonstrated the opium sparing effects of ketamine used as an adjuvant analgesic to opioids; while its side effects are acceptable. The adjuvant use of ketamine could be an interesting topic for clinicians managing acute pain in these patients. 
During recent years, there have been a number of studies stating their concerns regarding the possible unwanted effects of ketamine (40-46). These are usually related to the untoward effects of ketamine on neuro-developmental issues in pediatric patients and not in the adult population. Nonetheless, there are some alerts regarding possible apoptotic effects of ketamine on liver cells, especially in patients exposed to the drug frequently or as an abuse form (41, 47-49). In these studies, the authors are usually 'apprehensive' of the effects of ketamine on infants and children.

There are a number of limitations in our study; first of all, our patients did not include females and some unwanted effects of ketamine are more commonly seen in women (including the emergence reaction). In addition, our patients were only in the orthopedic ward, while other types of procedures that produce postoperative pain (like the GI tract, respiratory tract, or Central Nervous System surgeries) were not involved, and therefore the side effects of ketamine could be more severe in such cases. Overall, our study demonstrated the effectiveness of ketamine's analgesic effects when used as an adjuvant analgesic accompanied with morphine, and as a PCA analgesia in opium abuser patients undergoing orthopedic surgery.

\section{Acknowledgements}

The authors would like to acknowledge the generous help of the Taleghani Hospital OR, ward nurses and physicians, and also, the personnel of the Anesthesiology Research Center, Shahid Beheshti University of Medical Sciences, Tehran, Iran.

\section{Authors' Contribution}

Mastane Dahi-Taleghani, Benjamin Fazli, Mahshid Ghasemi and Maryam Vosoughian designed the study, collected the clinical data and prepared the manuscript. Ali Dabbagh had a role in the design, data analysis, writing and preparation of the manuscript.

\section{Financial Disclosure}

None of the authors have any financial disclosure.

\section{Funding/Support}

This study was supported financially in part by a research grant from the Anesthesiology Research Center, Shahid Beheshti University of Medical Sciences, Tehran, Iran.

\section{References}

1. American Society of Anesthesiologists Task Force on Acute Pain M. Practice guidelines for acute pain management in the perioperative setting: an updated report by the American Society of Anesthesiologists Task Force on Acute Pain Management. Anes- thesiology. 2012;116(2):248-73.

2. Azarasa M, Azarfarin R, Changizi A, Alizadehasl A. Substance use among Iranian cardiac surgery patients and its effects on shortterm outcome. Anesth Analg. 2009;109(5):1553-9.

3. Farrell C, McConaghy P. Perioperative management of patients taking treatment for chronic pain. BMJ. 2012;345:ee4148

4. Khademi H, Malekzadeh R, Pourshams A, Jafari E, Salahi R, Semnani S, et al. Opium use and mortality in Golestan Cohort Study: prospective cohort study of 50,000 adults in Iran. BMJ. 2012;344:ee2502

5. Safari F, Dabbagh A, Sharifnia M. The effect of adjuvant midazolam compared with fentanyl on the duration of spinal anesthesia with $0.5 \%$ bupivacaine in opium abusers. Korean J Anesthesiol. 2012;63(6):521-6.

6. Dabbagh A, Dahi-Taleghani M, Elyasi H, Vosoughian M, Malek B, Rajaei S, et al. Duration of spinal anesthesia with bupivacaine in chronic opium abusers undergoing lower extremity orthopedic surgery. Arch Iran Med. 2007;10(3):316-20.

7. Vosoughian M, Dabbagh A, Rajaei S, Maftuh H. The duration of spinal anesthesia with 5\% lidocaine in chronic opium abusers compared with nonabusers. Anesth Analg. 2007;105(2):531-3.

8. Bell RF, Dahl JB, Moore RA, Kalso E. Perioperative ketamine for acute postoperative pain. Cochrane Database Syst Rev. 2006;(1):CD004603.

9. Brown EN, Lydic R, Schiff ND. General anesthesia, sleep, and coma. N Engl J Med. 2010;363(27):2638-50.

10. Canet J, Castillo J. Ketamine: a familiar drug we trust. Anesthesiology. 2012;116(1):6-8.

11. Chazan S, Ekstein MP, Marouani N, Weinbroum AA. Ketamine for acute and subacute pain in opioid-tolerant patients. J Opioid Manag. 2008;4(3):173-80.

12. Galinski M, Dolveck F, Combes X, Limoges V, Smail N, Pommier V, et al. Management of severe acute pain in emergency settings: ketamine reduces morphine consumption. Am J Emerg Med. 2007;25(4):385-90.

13. Gharaei B, Jafari A, Aghamohammadi H, Kamranmanesh M, Poorzamani M, Elyassi $\mathrm{H}$, et al. Opioid-sparing effect of preemptive bolus low-dose ketamine for moderate sedation in opioid abusers undergoing extracorporeal shock wave lithotripsy: a randomized clinical trial. Anesth Analg. 2013;116(1):75-80.

14. Laskowski K, Stirling A, McKay WP, Lim HJ. A systematic review of intravenous ketamine for postoperative analgesia. Can J Anaesth. 2011;58(10):911-23.

15. Loftus RW, Yeager MP, Clark JA, Brown JR, Abdu WA, Sengupta DK, et al. Intraoperative ketamine reduces perioperative opiate consumption in opiate-dependent patients with chronic back pain undergoing back surgery. Anesthesiology. 2010;113(3):639-46.

16. Vadivelu N, Mitra S, Narayan D. Recent advances in postoperative pain management. Yale JBiol Med.2010;83(1):11-25.

17. Vosoughin M, Mohammadi S, Dabbagh A. Intravenous ketamine compared with diclofenac suppository in suppressing acute postoperative pain in women undergoing gynecologic laparoscopy. J Anesth. 2012;26(5):732-7.

18. Yeom JH, Chon MS, Jeon WJ, Shim JH. Peri-operative ketamine with the ambulatory elastometric infusion pump as an adjuvant to manage acute postoperative pain after spinal fusion in adults: a prospective randomized trial. Korean J Anesthesiol. 2012;63(1):54-8.

19. Elia N, Tramer MR. Ketamine and postoperative pain--a quantitative systematic review of randomised trials. Pain. 2005;113(12):61-70.

20. Joly V, Richebe P, Guignard B, Fletcher D, Maurette P, Sessler DI, et al. Remifentanil-induced postoperative hyperalgesia and its prevention with small-dose ketamine. Anesthesiology. 2005;103(1):147-55.

21. Subramaniam B, Subramaniam K, Pawar DK, Sennaraj B. Preoperative epidural ketamine in combination with morphine does not have a clinically relevant intra- and postoperative opioidsparing effect. Anesth Analg. 2001;93(5):1321-6.

22. Suzuki M. Role of N-methyl-D-aspartate receptor antagonists in postoperative pain management. Curr Opin Anaesthesiol. 
2009;22(5):618-22.

23. Hudcova J, McNicol E, Quah C, Lau J, Carr DB. Patient controlled opioid analgesia versus conventional opioid analgesia for postoperative pain. Cochrane Database Syst Rev. 2006;(4):CD003348.

24. Friede T, Kieser M. Sample size recalculation in internal pilot study designs: a review. Biom J. 2006;48(4):537-55.

25. Karlsson J, Engebretsen L, Dainty K, Isakos Scientific Committee. Considerations on sample size and power calculations in randomized clinical trials. Arthroscopy. 2003;19(9):997-9.

26. Pandis N, Polychronopoulou A, Eliades T. Sample size estimation: an overview with applications to orthodontic clinical trial designs. Am J Orthod Dentofacial Orthop. 2011;140(4):e141-6.

27. Schafer H, Timmesfeld N, Muller HH. An overview of statistical approaches for adaptive designs and design modifications. Biom J. 2006;48(4):507-20.

28. Asiabanha M, Asadikaram G, Rahnema A, Mahmoodi M, Hasanshahi G, Hashemi M, et al. Chronic Opium Treatment Can Differentially Induce Brain and Liver Cells Apoptosis in Diabetic and Non-diabetic Male and Female Rats. Korean J Physiol Pharmacol. 2011;15(6):327-32

29. Besharat S, Jabbari A, Besharat M. Opium as a fatal substance. Indian J Pediatr. 2008;75(11):1125-8.

30. Dabbagh A, Moghadam SF, Rajaei S, Mansouri Z, Manaheji HS Can repeated exposure to morphine change the spinal analgesic effects of lidocaine in rats? J Res Med Sci. 2011:16(10):1361-5.

31. Pourshams A, Saadatian-Elahi M, Nouraie M, Malekshah AF, Rakhshani N, Salahi R, et al. Golestan cohort study of oesophageal cancer: feasibility and first results. BrJ Cancer. 2005;92(1):176-81.

32. Saadat H, Ziai SA, Ghanemnia M, Namazi MH, Safi M, Vakili H, et al Opium addiction increases interleukin1 receptor antagonist(IL-1Ra) in the coronary artery disease patients. PLoS One. 2012;7(9):ee44939

33. Jabbary Moghaddam M, Ommi D, Mirkheshti A, Dabbagh A, Memary E, Sadeghi A, et al. Effects of clonidine premedication upon postoperative shivering and recovery time in patients with and without opium addiction after elective leg fracture surgeries. Anesth Pain Med. 2013;2(3):107-10.

34. Javid MJ, Hajijafari M, Hajipour A, Makarem J, Khazaeipour Z Evaluation of a low dose ketamine in post tonsillectomy pain relief: a randomized trial comparing intravenous and subcutaneous ketamine in pediatrics. Anesth Pain Med. 2012;2(2):85-9.

35. Dabbagh A. Clonidine: An old friend newly rediscovered. Anesth Pain Med. 2011;1(1):8-9.

36. Najafi M, Sheikhvatan M. Does analgesic effect of opium hamper the adverse effects of severe coronary artery disease on quality of life in addicted patients? Anesth Pain Med. 2012;2(1):22-7.

37. Behdad S, Hajiesmaeili MR, Abbasi HR, Ayatollahi V, KhadivZ, Sedaghat A. Analgesic Effects of Intravenous Ketamine during Spinal
Anesthesia in Pregnant Women Undergone Caesarean Section; A Randomized Clinical Trial. Anesth Pain Med. 2013;3(2):230-3.

38. Hosseini Jahromi SA, Hosseini Valami SM, Hatamian S. Comparison between effect of lidocaine, morphine and ketamine spray on post-tonsillectomy pain in children. Anesth Pain Med 2012;2(1):17-21.

39. Khajavi M, Emami A, Etezadi F, Safari S, Sharifi A, Shariat Moharari R. Conscious Sedation and Analgesia in Colonoscopy: Ketamine/ Propofol Combination has Superior Patient Satisfaction Versus Fentanyl/Propofol. Anesth Pain Med. 2013;3(1):208-13.

40. Bosnjak ZJ, Yan Y, Canfield S, Muravyeva MY, Kikuchi C, Wells CW, et al. Ketamine induces toxicity in human neurons differentiated from embryonic stem cells via mitochondrial apoptosis pathway. Curr Drug Saf. 2012;7(2):106-19.

41. Brambrink AM, Evers AS, Avidan MS, Farber NB, Smith DJ, Martin LD, et al. Ketamine-induced neuroapoptosis in the fetal and neonatal rhesus macaque brain. Anesthesiology. 2012;116(2):372-84

42. Braun S, Gaza N, Werdehausen R, Hermanns H, Bauer I, Durieux $\mathrm{ME}$, et al. Ketamine induces apoptosis via the mitochondrial pathway in human lymphocytes and neuronal cells. Br J Anaesth. 2010;105(3):347-54.

43. Engelhard K, Werner C, Eberspacher E, Bachl M, Blobner M Hildt E, et al. The effect of the alpha 2-agonist dexmedetomidine and the $\mathrm{N}$-methyl-D-aspartate antagonist $\mathrm{S}(+)$-ketamine on the expression of apoptosis-regulating proteins after incomplete cerebral ischemia and reperfusion in rats. Anesth Analg. 2003;96(2):524-31.

44. Ponten E, Viberg H, Gordh T, Eriksson P, Fredriksson A. Clonidine abolishes the adverse effects on apoptosis and behaviour after neonatal ketamine exposure in mice. Acta Anaesthesiol Scand. 2012;56(8):1058-65.

45. Yagmurdur H, Aksoy M, Arslan M, Baltaci B. The effects of propofol and ketamine on gut mucosal epithelial apoptosis in rats af ter burn injury. EurJ Anaesthesiol. 2007;24(1):46-52.

46. Zhang X, Paule MG, Newport GD, Sadovova N, Berridge MS, Apana SM, et al. MicroPET imaging of ketamine-induced neuronal apoptosis with radiolabeled DFNSH.J Neural Transm. 2011;118(2):203-11.

47. Bai X, Yan Y, Canfield S, Muravyeva MY, Kikuchi C, Zaja I, et al. Ketamine enhances human neural stem cell proliferation and induces neuronal apoptosis via reactive oxygen species-mediated mitochondrial pathway. Anesth Analg. 2013;116(4):869-80.

48. Liu JR, Liu Q, Li J, Baek C, Han XH, Athiraman U, et al. Noxious stimulation attenuates ketamine-induced neuroapoptosis in the developing rat brain. Anesthesiology. 2012;117(1):64-71.

49. Persson J. Wherefore ketamine? Curr Opin Anaesthesiol. 2010;23(4):455-60. 